\title{
Aortic Calcification Affects Noninvasive Estimates of Central Blood Pressure in Patients with Severe Chronic Kidney Disease
}

\author{
Rasmus Kirkeskov Carlsen ${ }^{a}$ b Simon Winther $^{c}$ Christian D. Peters ${ }^{a}, b$ \\ Esben Laugesen ${ }^{b}, \mathrm{~d}, \mathrm{e}$ Dinah S. Khatira, ${ }^{\mathrm{b}}$ Hans E. Bøtker ${ }^{c}$ Morten Bøttcher ${ }^{f}$ \\ Per Ivarsen ${ }^{a} \quad$ My Svensson $^{9}$ Niels Henrik Buus ${ }^{\mathrm{a}}{ }^{\mathrm{h}}$ \\ a Department of Renal Medicine, Aarhus University Hospital, Aarhus, Denmark; ${ }^{b}$ Institute \\ of Clinical Medicine, Aarhus University, Aarhus, Denmark; ' ${ }^{\circ}$ Department of Cardiology, \\ Aarhus University Hospital, Aarhus, Denmark; d Department of Endocrinology and Internal \\ Medicine, Aarhus University Hospital, Aarhus, Denmark; e Danish Diabetes Academy, \\ Odense University Hospital, Odense, Denmark; ${ }^{\mathrm{f}}$ Department of Cardiology, Hospital Unit \\ West, Herning, Denmark; ${ }^{9}$ Department of Nephrology, Division of Medicine, Akershus \\ University Hospital, Oslo, Norway; ${ }^{\text {h}}$ Department of Biomedicine, Aarhus University, \\ Aarhus, Denmark
}

\section{Keywords}

Aortic calcifications - Blood pressure Central blood pressure - Invasive blood pressure .

Chronic kidney disease - Generalized transfer function - Pulse wave velocity

\begin{abstract}
Background: Central blood pressure (BP) assessed noninvasively considerably underestimates true invasively measured aortic BP in chronic kidney disease (CKD) patients. The difference between the estimated and the true aortic BP increases with decreasing estimated glomerular filtration rates (eGFR). The present study investigated whether aortic calcification affects noninvasive estimates of central BP. Methods: Twenty-four patients with CKD stage 4-5 undergoing coronary angiography and an aortic computed tomography scan were included (63\% males, age [mean \pm SD ] $53 \pm 11$ years, and eGFR $9 \pm 5 \mathrm{~mL} / \mathrm{min} / 1.73 \mathrm{~m}^{2}$ ). Invasive aortic BP was measured through the angiography catheter, while non-invasive central BP was obtained using radial artery tonometry with a SphygmoCor ${ }^{\circledR}$ device. The Agatston calcium score (CS) in the aorta was quantified on CT scans using the CS on CT scans. Results: The invasive aortic systolic BP (SBP) was $152 \pm 23 \mathrm{~mm} \mathrm{Hg}$, while the estimated central SBP was 133 $\pm 20 \mathrm{~mm} \mathrm{Hg}$. Ten patients had a CS of 0 in the aorta, while 14 patients had a CS $>0$ in the aorta. The estimated central SBP was lower than the invasive aortic SBP in patients with aortic calcification compared to patients without (mean difference $8 \mathrm{~mm} \mathrm{Hg}, 95 \% \mathrm{Cl} 0.3-16 ; p=$ 0.04). The brachial SBP was lower than the aortic SBP in patients with aortic calcification com-
\end{abstract}




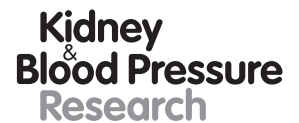

Research

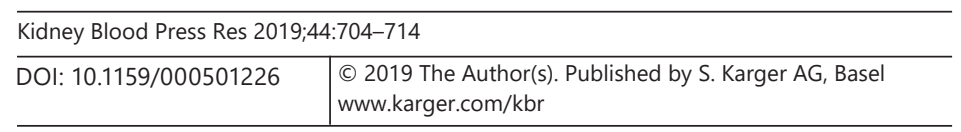

Carlsen et al.: Aortic Calcification and Central BP in CKD

pared to patients without (mean difference $10 \mathrm{~mm} \mathrm{Hg}, 95 \% \mathrm{Cl} 2-19 ; p=0.02$ ). Conclusion: In patients with advanced CKD the presence of aortic calcification is associated with a higher difference between invasively measured central aortic BP and non-invasive estimates of central BP as compared to patients without calcifications.

\section{Introduction}

Optimal blood pressure (BP) assessment is important for the correct treatment of hypertension in chronic kidney disease (CKD) as treatment of hypertension reduces both CKD progression and the cardiovascular risk $[1,2]$. Usually BP recordings are performed as cuffbased measurements at the upper arm, relying on the assumption that this is a reasonable representation of the central BP to which the target organs are exposed. However, several studies have demonstrated a marked difference in systolic BP (SBP) measured within the aorta compared to the peripheral arteries [3-5]. Accordingly, it has been suggested that antihypertensive treatment should be based on the aortic BP rather than the brachial BP [6], and several devices are now available for noninvasive estimation of the aortic BP.

In young healthy individuals the SBP increases as the pulse wave travels from the aorta to the peripheral arteries such as the brachial artery. This results in a higher SBP in the brachial artery than in the aorta, while the diastolic BP (DBP) and the mean arterial BP (MAP) remain fairly constant [7]. This phenomenon is called pulse pressure amplification. With aging, pulse pressure amplification decreases, attenuating the pressure gain towards the peripheral arteries alongside an increase in pulse pressure in the central arteries. This is commonly believed to be caused by increased arterial stiffness due to arteriosclerosis. This phenomenon increases with age and diseases such as CKD and diabetes [7].

Invasive aortic SBP has previously been compared with noninvasive estimates derived by arterial tonometry, and the reported differences have been with wide limits of agreement $[4,5,8,9]$. In a recent publication we presented the association between invasive aortic SBP and peripheral measurements of SBP either by standard brachial SBP or estimates of central (aortic) SBP using the SphygmoCor ${ }^{\circledR}$ device [10]. In our cohort of CKD patients, the difference between invasive aortic SBP and estimated central SBP increased with decreasing renal function. Likewise, the difference between brachial SBP and invasive aortic SBP increased with decreasing renal function. Thus, both brachial and estimated central SBP underestimate the true central BP in aorta in patients with advanced CKD. As the difference between aortic and estimated central SBP was partly dependent on the pulse wave velocity (PWV), the increased prevalence of arterial media calcifications in CKD could influence the difference between peripheral and central BP and thereby explain our findings [11].

We therefore hypothesized that CKD patients with arterial calcification would have higher BP differences between the aorta and the brachial artery. To investigate this further, we examined CT scans of the aorta from a subgroup of CKD patients in our cohort to determine whether the presence of aortic calcification is associated with differences in BP when comparing invasively measured aortic BP with estimated central BP or brachial BP, respectively.

\section{Methods}

Eighty-three CKD patients referred for elective coronary angiography (CAG) were included in the main study as previously described [10]. Participants had at least 3 measurements of estimated glomerular filtration rate (eGFR) within the previous 3 months as deter- 


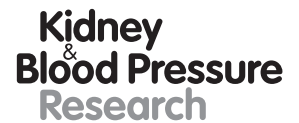

Kidney
Blood Pressure
Research \begin{tabular}{l|l}
\hline Kidney Blood Press Res 2019:44:704-714 \\
\hline DOI: 10.1159/000501226 & $\begin{array}{l}\text { ○ 2019 The Author(s). Published by S. Karger AG, Basel } \\
\text { www.karger.com/kbr }\end{array}$ \\
\hline
\end{tabular}

Carlsen et al.: Aortic Calcification and Central BP in CKD

mined by the Chronic Kidney Disease Epidemiology Collaboration (CKD-EPI) equation [12]. eGFR was set to $5 \mathrm{~mL} / \mathrm{min} / 1.73 \mathrm{~m}^{2}$ in dialysis patients with residual renal function and to 0 in patients with anuria $(<100 \mathrm{~mL} /$ day $)$. The present post hoc analysis included only participants who also took part in the Angiographic CT of Renal bone and vascular disease (ACTOR) study [13]. These patients all had a cardiac computed tomography (CT) in addition to an invasive CAG performed as part of a screening program before kidney transplantation. Exclusion criteria were cardiac arrhythmia or known subclavian or brachial artery stenosis. The investigations were performed between March 14, 2013, and January 27, 2014.

Cardiac CT scans were performed in a dual-source scanner (SOMATOM Definition Flash, Siemens Healthcare, Erlangen, Germany) as described in detail earlier [13]. In brief, a nonenhanced scan of the heart was conducted in all of the patients. The tube voltage was $120 \mathrm{kV}$ and the tube current was automatic adjusted. Axial images were reconstructed using a 3-mm slice thickness. The Agatston method was used to measure coronary artery calcium scores and for quantification of calcium scores in the ascending and descending aorta using full fieldof-view images [14].

Brachial BP was measured with a Microlife BP A100 PLUS automatic oscillometric BP monitor (Widnau, Switzerland), which fulfills current recommendations [15]. All of the participants had BP measurements on both arms and if the difference in SBP or DBP exceeded $5 \mathrm{~mm} \mathrm{Hg}$ the arm with the higher pressure was used, except in dialysis patients with an arteriovenous fistula, in whom the nonfistula arm was used. The estimated central BP was determined based on the radial artery pressure waveform recorded noninvasively using SphygmoCor equipment (AtCor Medical, Itasca, IL, USA) and software (version 8.2; AtCor Medical, Sydney, Australia). The recording time was $10 \mathrm{~s}$. The waveforms were calibrated with the brachial SBP and DBP.

Brachial and estimated central BP were measured on the same arm sequentially. All BP measurements were recorded within $30 \mathrm{~s}$. To test the accuracy of the general transfer function, we estimated the central SBP using invasively measured aortic BP for calibration (MAP and DBP).

Invasive BP was measured in the ascending aorta with a fluid-filled 6-French Boston Scientific Expo Angiographic catheter (Natick, MA, USA) or a 6-French Medtronic Launcher Coronary Guide catheter (Minneapolis, MN, USA) attached to an NAMIC transducer (Navilyst Medical, Marlborough, MA, USA). The tranducers were calibrated before each examination. Catheters were inserted through a femoral or radial sheath into the ascending aorta and flushed every 2 min during the investigation. SBP and DBP were determined as the average of the pressure peaks during 10-s recording periods, and MAP was determined as the area under the curve by the recording equipment software (Philips Xper Physiomonitoring 5; Philips, Amsterdam, The Netherlands; or Siemens Axiom Sensis XP; Siemens, Munich, Germany).

PWV was measured on the same day as the invasive BP was obtained before the patient underwent CAG. Carotid femoral PWV and carotid radial PWV were measured with applanation tonometry sequentially at the carotid and femoral arteries or the carotid and radial arteries. Details regarding PWV measurements have previously been published [10].

\section{Statistical Analysis}

Data distribution was evaluated with histograms and QQ plots. Baseline data are presented as means \pm SD or as medians (range) if data were not normally distributed. Between-group differences were tested using an unpaired Student $t$ test. If data were skewed, even after logarithmic transformation, groups were compared using a Wilcoxon-MannWhitney test. Categorical variables are presented as numbers (\%) and were compared using Pearson's $\chi^{2}$ test. Between-group differences were tested with a one-way ANOVA when more than 2 groups were present. 
Table 1. Characteristics of the patients

\begin{tabular}{|c|c|}
\hline Age, years & $53 \pm 11$ \\
\hline Males & $15(63)$ \\
\hline BMI & $24 \pm 3$ \\
\hline Smokers (current/previous/never), $n$ & $9 / 8 / 7$ \\
\hline Diabetes & $6(25)$ \\
\hline Ejection fraction (range), \% & $60(55-65)$ \\
\hline \multicolumn{2}{|l|}{ CKD status } \\
\hline $\mathrm{eGFR}, \mathrm{mL} / \mathrm{min} / 1.73 \mathrm{~m}^{2}$ & $9 \pm 5$ \\
\hline Dialysis & $6(25)$ \\
\hline \multicolumn{2}{|l|}{ Antihypertensive medication } \\
\hline Medications per patient, $n$ & $4(0-5)$ \\
\hline ACE inhibitors & $8(33)$ \\
\hline ARB & $11(24)$ \\
\hline$\beta$-blocker & $16(67)$ \\
\hline Calcium channel blocker & $17(71)$ \\
\hline Diuretics & $21(88)$ \\
\hline Nitrates & $1(4)$ \\
\hline Glycerol nitrate during CAG & $20(83)$ \\
\hline \multicolumn{2}{|l|}{$\mathrm{BP}, \mathrm{mm} \mathrm{Hg}$} \\
\hline Brachial SBP & $146 \pm 20$ \\
\hline Aortic SBP & $152 \pm 23$ \\
\hline Estimated central SBP & $133 \pm 20$ \\
\hline Brachial DBP & $88 \pm 11$ \\
\hline Aortic DBP & $82 \pm 11$ \\
\hline Estimated central DBP & $89 \pm 11$ \\
\hline \multicolumn{2}{|l|}{$\mathrm{PWV}, \mathrm{m} / \mathrm{s}$} \\
\hline Carotid-femoral & $9.9 \pm 2.0$ \\
\hline Carotid-radial & $8.8 \pm 1.1$ \\
\hline \multicolumn{2}{|l|}{ CS (range) } \\
\hline Coronary arteries & $9(0-4,657)$ \\
\hline Ascending aorta & $0(0-414)$ \\
\hline Descending aorta & $12(0-1,598)$ \\
\hline
\end{tabular}

The total number of patients is 24 . Values are presented as means \pm SD or numbers (\%) unless otherwise stated. The eGFR was set to $5 \mathrm{~mL} /$ $\min / 1.73 \mathrm{~m}^{2}$ in dialysis patients with residual renal function and to 0 in patients with anuria $(<100 \mathrm{~mL} /$ day). ACE, angiotensin-converting enzyme; ARB, angiotensin receptor blocker.

First, the accuracy of the general transfer function was evaluated by comparing the invasive aortic SBP with the estimated central BP calibrated with the invasively measured aortic mean BP and DBP. Second, the invasive aortic BP was compared with the brachial SBP and the estimated central SBP, respectively. The central SBP was obtained by using normal calibration with noninvasively obtained brachial SBP and DBP. Third, patients were categorized into 2 groups with or without aortic calcification in order to compare all SBP differences in patients with and without aortic calcification. Data were analyzed using STATA 13 for Windows (StataCorp LP, College State, TX, USA).

\section{Results}

\section{Patient Characteristics}

Twenty-nine CKD patients from the primary study who also underwent aortic CT scans were included in this substudy. Three patients were excluded because the measurements 
Table 2. Patient characteristics according to the aortic calcium score

\begin{tabular}{|c|c|c|c|}
\hline & $\begin{array}{l}\text { No aortic } \\
\text { calcifications }\end{array}$ & $\begin{array}{l}\text { Aortic } \\
\text { calcifications }\end{array}$ & $p$ value $^{\mathrm{a}}$ \\
\hline Patients, $n$ & 10 & 14 & \\
\hline Age, years & $46 \pm 6$ & $58 \pm 11$ & 0.01 \\
\hline Males & $7(70)$ & 8 (57) & $0.52^{\mathrm{b}}$ \\
\hline BMI & $26 \pm 3$ & $23 \pm 3$ & 0.07 \\
\hline Smokers (current/previous/never), $n$ & $4 / 2 / 4$ & $5 / 6 / 3$ & NA \\
\hline Diabetes & $4(40)$ & $2(14)$ & $0.15^{\mathrm{b}}$ \\
\hline Ejection fraction (range), \% & $60(55-65)$ & $60(55-65)$ & $0.71^{\mathrm{c}}$ \\
\hline \multicolumn{4}{|l|}{ CKD status } \\
\hline $\mathrm{eGFR}, \mathrm{mL} / \mathrm{min} / 1.73 \mathrm{~m}^{2}$ & $11 \pm 6$ & $8 \pm 5$ & 0.17 \\
\hline Dialysis & $1(10)$ & $5(36)$ & $0.15^{\mathrm{b}}$ \\
\hline \multicolumn{4}{|l|}{ Antihypertensive medication } \\
\hline Medications per patient, $n$ & $4(0-5)$ & $3(0-4)$ & $0.048^{c}$ \\
\hline ACE inhibitor & $5(50)$ & $3(21)$ & $0.14^{\mathrm{b}}$ \\
\hline ARB & $6(60)$ & $5(36)$ & $0.24^{\mathrm{b}}$ \\
\hline Beta-blocker & $6(60)$ & $10(71)$ & $0.56^{\mathrm{b}}$ \\
\hline Calcium channel blocker & $9(90)$ & $8(57)$ & $0.08^{\mathrm{b}}$ \\
\hline Diuretics & $9(90)$ & $12(86)$ & $0.75^{\mathrm{b}}$ \\
\hline Nitrates & $1(10)$ & $0(0)$ & $0.23^{\mathrm{b}}$ \\
\hline Glycerol nitrate during CAG & $9(90)$ & $11(79)$ & $0.46^{\mathrm{b}}$ \\
\hline \multicolumn{4}{|l|}{$\mathrm{BP}, \mathrm{mm} \mathrm{Hg}$} \\
\hline Brachial SBP & $143 \pm 19$ & $149 \pm 20$ & 0.47 \\
\hline Aortic SBP & $143 \pm 23$ & $159 \pm 22$ & 0.09 \\
\hline Estimated central SBP & $128 \pm 16$ & $136 \pm 23$ & 0.35 \\
\hline Brachial DBP & $89 \pm 9$ & $88 \pm 12$ & 0.94 \\
\hline Aortic DBP & $81 \pm 10$ & $82 \pm 12$ & 0.82 \\
\hline Estimated central DBP & $90 \pm 9$ & $89 \pm 12$ & 0.92 \\
\hline \multicolumn{4}{|l|}{$\mathrm{PWV}, \mathrm{m} / \mathrm{s}$} \\
\hline Carotid-femoral & $8.8 \pm 2.0$ & $10.8 \pm 1.6$ & 0.01 \\
\hline Carotid-radial & $8.7 \pm 0.9$ & $8.8 \pm 1.3$ & 0.79 \\
\hline \multicolumn{4}{|l|}{ CS (range) } \\
\hline Coronary arteries & $0(0-256)$ & $135(0-4,657)$ & \\
\hline Ascending aorta & $0(0)$ & $0(0-414)$ & \\
\hline Descending aorta & $0(0)$ & $160(0-1,598)$ & \\
\hline
\end{tabular}

Data are means \pm SD or numbers (\%) unless otherwise indicated. The eGFR was set to $5 \mathrm{~mL} / \mathrm{min} / 1.73 \mathrm{~m}^{2}$ in dialysis patients with residual renal function and to 0 in patients with anuria $(<100 \mathrm{~mL} / \mathrm{day})$. ACE, angiotensin-converting enzyme; ARB, angiotensin receptor blocker. ${ }^{a}$ Student's $t$ test. ${ }^{\mathrm{b}} \chi^{2}$ test. ${ }^{\mathrm{c}}$ WilcoxonMann-Whitney test.

could not be performed, and 2 patients were excluded because of arrhythmia. The final study cohort consisted of 24 patients ( $29 \%$ of the original 83 patients included). The median time between the CT scan and the coronary angiography was 39 days (range 7-197). The mean CT scan z-axis distance was $14.6 \pm 1.7 \mathrm{~cm}$ and the mean aorta ascending and descending lengths included in the scan were $6.4 \pm 1.1$ and $15.0 \pm 1.8 \mathrm{~cm}$.

Baseline characteristics are presented in Table 1. Ten patients had an Agatston calcium score (CS) of 0 in both ascending and descending aorta; 2 patients had ascending aortic CS $>0$, while 8 patients had descending aortic CS $>0$ and 4 patients had both ascending and descending aortic $\mathrm{CS}>0$.

When comparing patients according to the presence or absence of aortic calcification (Table 2), the groups were different regarding age and carotid-femoral PWV but not 
Fig. 1. Estimated minus invasive aortic SBP in patients with and without aortic calcifications. Lines represent mean values for the group without aortic calcifications $(-15 \mathrm{~mm} \mathrm{Hg}$ ) and the group with calcifications $(-23 \mathrm{~mm} \mathrm{Hg})$.

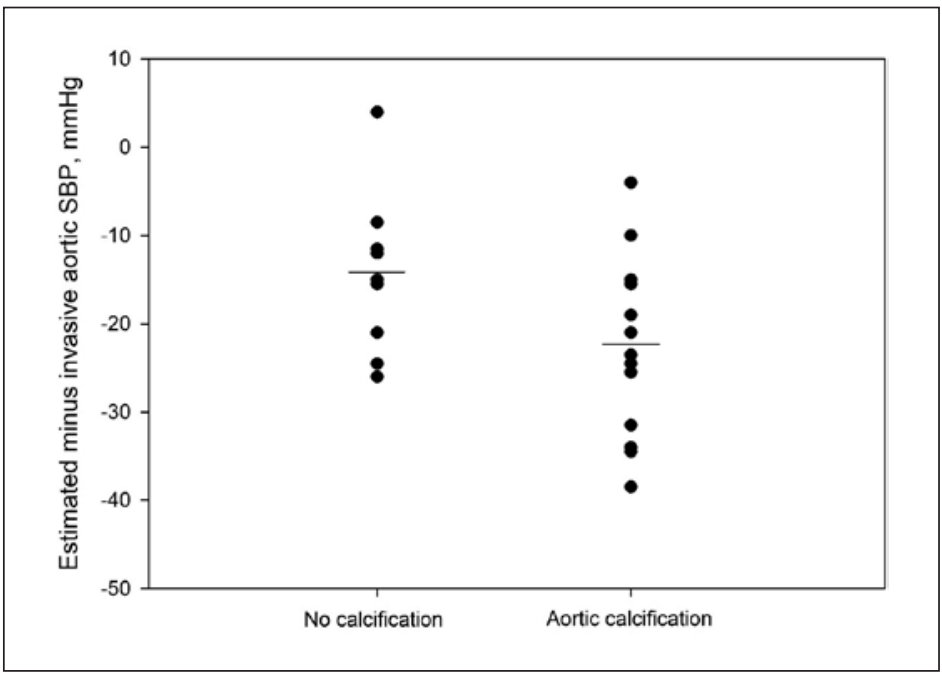

Fig. 2. Brachial minus invasive aortic SBP in patients with and without aortic calcifications. Lines represent mean values for the group without aortic calcifications (0 $\mathrm{mm} \mathrm{Hg}$ ) and the group with calcifications $(-10 \mathrm{~mm} \mathrm{Hg})$.

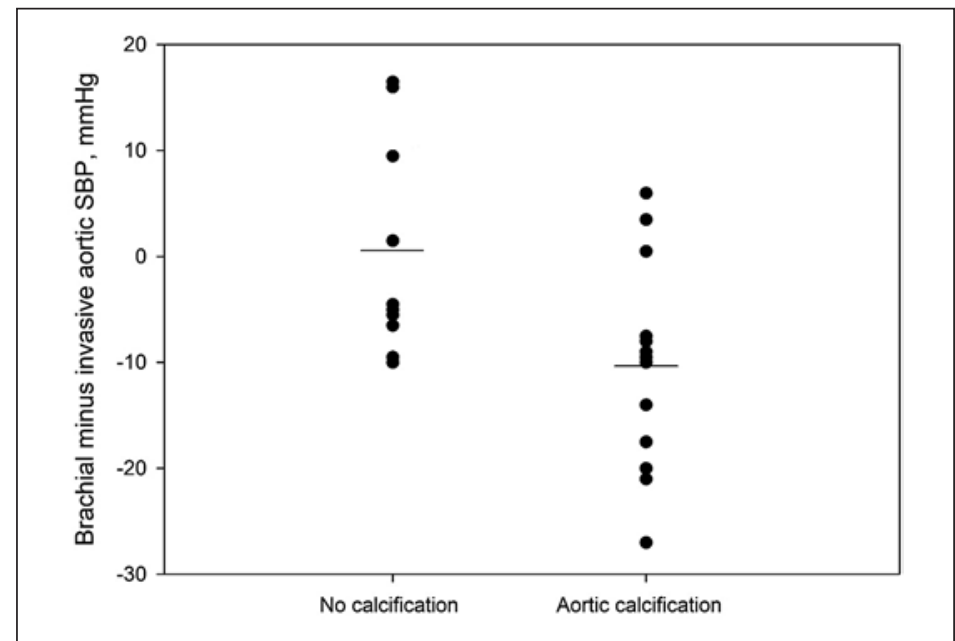

gender, eGFR, brachial BP, or carotid-radial PWV. Patients with aortic calcifications received more antihypertensive drugs and there was a tendency towards a greater use of calcium channel blockers, but apart from that antihypertensive medication was similar. There was an equal distribution of patients with diabetes, and smoking status was not significantly different.

\section{Accuracy of the Generalized Transfer Function}

Invasively calibrated estimated central SBP and invasive aortic SBP were not significantly different when patients with and without aortic calcification were compared (mean difference $2 \mathrm{~mm} \mathrm{Hg}$, 95\% CI -3 to $8 ; p=0.42$ ).

\section{Difference between Invasive Aortic SBP and Estimated Central SBP}

The estimated central SBP was lower than the invasive aortic SBP in patients with aortic calcification compared to patients without (Fig. 1) (mean difference $8 \mathrm{~mm} \mathrm{Hg}$, 95\% CI 0.3-16; $p=0.04)$. 
Fig. 3. Estimated minus invasive aortic SBP according to the degree of aortic calcification. Group A: no calcification in either the ascending or the descending aorta. Group B: calcification in either the ascending or the descending aorta. Group C: calcification in both the ascending and the descending aortas. Lines represent mean values for group A (-15 mm $\mathrm{Hg})$, group B (-21 mm $\mathrm{Hg})$, and group C $(-29 \mathrm{~mm} \mathrm{Hg})$.

Fig. 4. Brachial minus invasive aortic SBP according to the degree of aortic calcification. Group A: no calcification in either the ascending or the descending aorta. Group B: calcification in either the ascending or the descending aorta. Group C: calcification in both the ascending and the descending aortas. Lines represent mean values for group A ( $0 \mathrm{~mm} \mathrm{Hg}$ ), group $\mathrm{B}(-8 \mathrm{~mm} \mathrm{Hg})$, and group C (-16

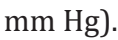
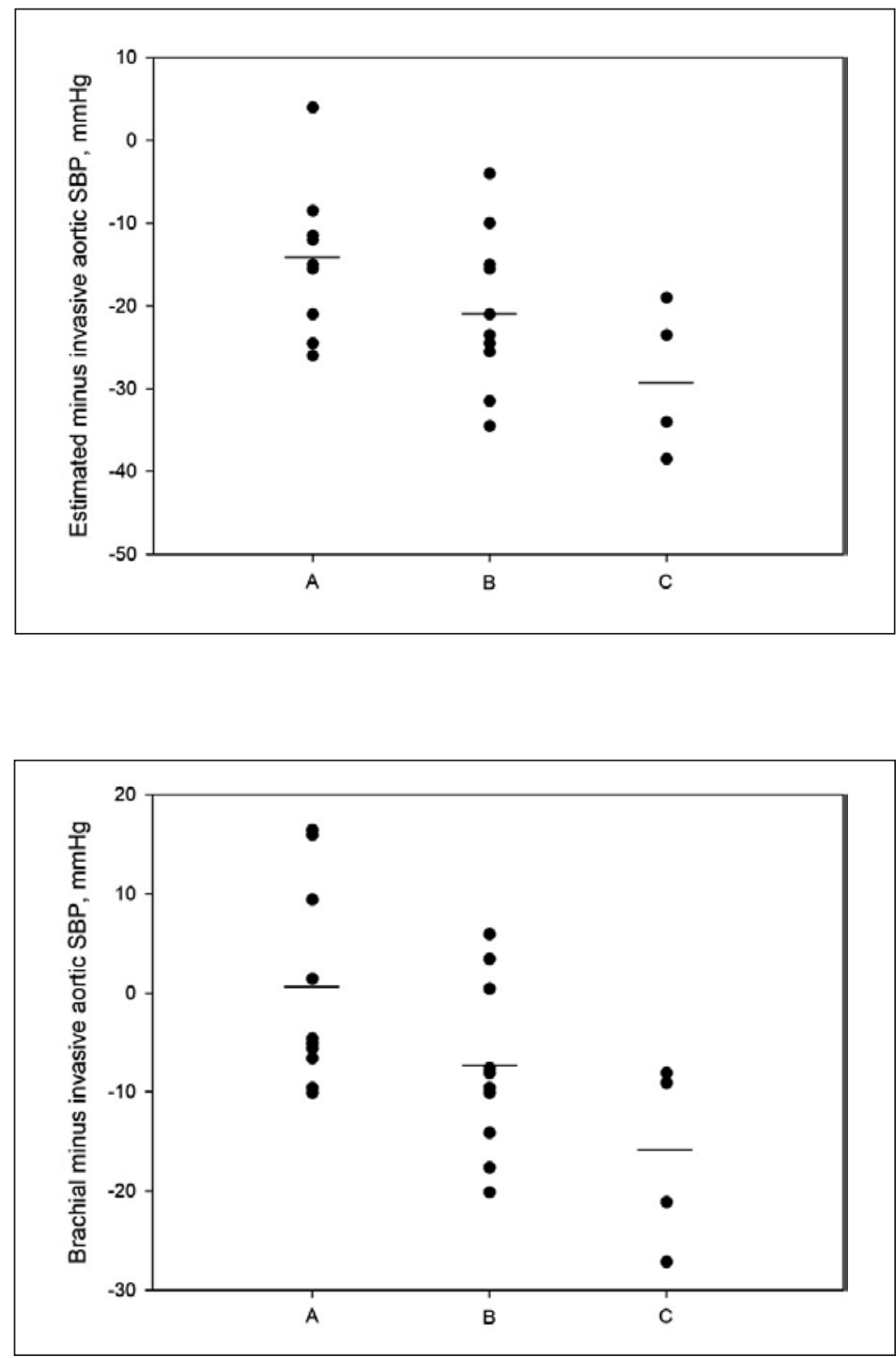

Difference between Invasive Aortic and Brachial SBP

The brachial SBP was lower than the aortic SBP in patients with aortic calcium compared to patients without (Fig. 2) (mean difference $10 \mathrm{mg} \mathrm{Hg}$, 95\% CI 2-19; $p=0.02$ ).

\section{Association between BP Differences and Calcification Placement}

To investigate whether a stepwise increased aortic calcification increased the BP differences, we categorized 3 groups as shown in Figure 3. Group A included patients with no calcification in either the ascending or the descending aorta. Group B comprised patients with calcification in either the ascending or the descending aorta. Group C included patients with calcification in both the ascending and the descending aortas. The difference between invasively calibrated estimated central SBP and aortic SBP was not significantly different in the 3 groups ( $p=0.51$ ). The difference between central SBP and invasive aortic SBP was significantly different between the groups $(p=0.04)$ and the difference between brachial SBP and invasive aortic SBP was also significantly different in the 3 groups (Fig. 4) ( $p=$ 0.02). 


\section{Kidney \\ Blood Pressure \\ Research}

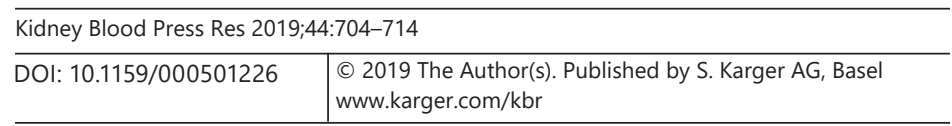

Carlsen et al.: Aortic Calcification and Central BP in CKD

\section{Coronary Artery Calcification}

In general, the presence of calcification(s) in the coronary arteries had no association with BP differences. Invasively calibrated estimated central SBP was not significantly different compared to invasive aortic SBP in patients with and without coronary artery calcification (mean difference $0 \mathrm{~mm} \mathrm{Hg}, 95 \% \mathrm{CI}-5.4$ to $6.0, p=0.90$ ). The estimated central SBP was not significantly different from the invasive aortic SBP in patients with and without coronary artery calcification (mean difference $1 \mathrm{~mm} \mathrm{Hg}$, CI: -7.8 to 9.6, $p=0.82$ ). Finally, the brachial SBP was not significantly different from the invasive SBP in patients with coronary calcification compared to patients without coronary artery calcification (mean difference $0 \mathrm{~mm} \mathrm{Hg}$, $95 \%$ CI -9.5 to $9.2 ; p=0.97$ ).

\section{Discussion}

The main finding of this study is that aortic calcification is associated with an increased difference between invasively measured central aortic BP and noninvasive estimates of central BP in patients with severe CKD. Accordingly, the difference between estimated and invasive aortic SBP increased from 8 to $10 \mathrm{~mm} \mathrm{Hg}$ in patients with calcification in the aorta. The interpretation of our findings is that noninvasive BP (both brachial BP and estimated central BP) underestimates the invasive aortic SBP in patients with CKD and aortic calcifications.

The groups with and without aortic calcifications were different in terms of age and the amount of antihypertensive medication, potentially implying a selection bias. However, in our main study with 124 participants, BP differences were not associated with age or number of antihypertensive medications, either in the entire study group or in patients with CKD [10]. These previous findings from the larger cohort suggest that age is not responsible for the observed BP differences.

The close association between aortic calcification and PWV is well known from previous publications [16] and fits well with the hypothesis that CKD results in accelerated vascular aging and increased arterial stiffness [7]. In our study a higher carotid-femoral PWV was found both in older patients and in patients with pronounced aortic calcification. However, because of the cross-sectional design we could not investigate the causal relationship between age, arterial stiffness, and BP differences between the aorta and estimated central SBP or the brachial artery. Previously we found increased differences between invasively measured aortic SBP and estimated and brachial SBP in patients with CKD and increased PWV [10]. Given these findings it is perhaps of little surprise that this sub study found a similar correlation between the presence of aortic calcifications and BP. However, the difference was more pronounced than we expected.

Despite the fact that aortic calcification was significantly associated with a large difference between invasively measured aortic BP and noninvasively obtained central BP, no BP differences were found when groups were compared based on coronary artery calcification. This may be due to the pathogenesis of cardiovascular disease in CKD with a higher prevalence of arterial media calcification, also called Mönckeberg's sclerosis, which is different from the agerelated intimal atherosclerosis. Media calcification is closely related to diabetes and disorders of mineral metabolism, including abnormalities in calcium, phosphorus, parathyroid hormone, and vitamin D unique to the CKD population $[11,17]$. Intimal atherosclerosis, however, is also prevalent in CKD often with more calcified plaques as compared to non-CKD patients. The combined development of both media and intima calcification in CKD is often described as accelerated or early vascular aging. The BP differences found in the present study may primarily be driven by generalized media calcification and not intimal atherosclerosis. This could explain 


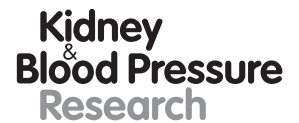

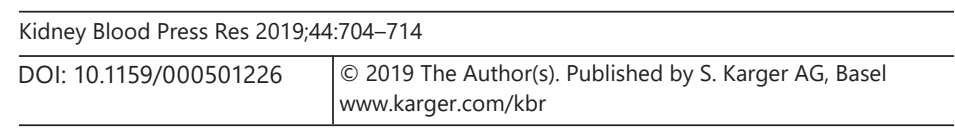

Carlsen et al.: Aortic Calcification and Central BP in CKD

why we in an earlier study found a close agreement between estimated central SBP and invasively measured aortic SBP in non-CKD patients with diabetes [18].

Patients without CKD usually have a higher SBP in the brachial artery than in the aorta, with a reported difference between 2 and $11 \mathrm{~mm} \mathrm{Hg}[4,5,8,9,18,19]$. In the present study, patients with CKD stage 4-5 and aortic calcification had a markedly lower brachial SBP than aortic SBP, i.e., around $10 \mathrm{~mm} \mathrm{Hg}$. It has previously been hypothesized that central aortic BP is more clinically relevant than peripheral BP since it better represents the BP in vulnerable target organs such as the brain, heart, and kidneys [6]. If this is true, then we should aim for a markedly lower target BP in patients with severe CKD and known calcifications.

A previous study found no additional prognostic value of invasively measured aortic SBP in terms of cardiovascular outcomes and all-cause mortality compared with office BP in patients with stable angina pectoris [20]. However, contrary to our findings, this study found an aortic SBP that was very similar to the brachial SBP, with an average difference of $0 \mathrm{~mm}$ $\mathrm{Hg}$, but the study did not focus specifically on CKD patients. A recent large study in CKD patients based on the Chronic Renal Insufficiency Cohort Study (CRIC) cohort found no additional value of noninvasively obtained central BP in comparison with normal brachial BP in terms of cardiovascular disease outcome or mortality [21]. However, invasive BP measurements were not performed in this study and are usually not available in the clinical setting apart from patients undergoing CAG.

The main limitation of our study is the limited number of patients, which hampers the assessment of relevant contributing factors such as diabetes, age, and time on dialysis treatment. Secondly, we investigated a selected group of patients with severe CKD and the results might not be generalizable to patients with mild or moderate CKD. Moreover, the CKD patients in our cohort were all investigated as part of a screening process before kidney transplantation and therefore most likely had less comorbidity compared to the overall CKD population. Third, we had no measurements of carotid intima-media thickness or arterial distensibility apart from PWV and this could have affected the interpretation of the results. Finally, although we did test the accuracy of the general transfer function-derived central SBP using calibration with invasively obtained MAP and DBP from aorta, we did not perform invasive intra-arterial BP measurements in the radial, brachial, or femoral arteries. An important strength of our data in comparison to previous studies is the simultaneous recording of invasive and non-invasive BP measurements and the short time span to the CT scan.

In conclusion, this study in patients with severe CKD found a significantly increased difference between invasively measured central aortic BP and noninvasive estimates of central BP in patients with aortic calcifications compared to patients without aortic calcifications. Aortic calcification also significantly affected the difference between brachial and invasively measured central SBP. This may question the usefulness of noninvasive estimates of central BP in CKD patients with aortic calcifications.

\section{Acknowledgement}

All of the project participants are thanked for their time and involvement. The staff at the Cardiology Lab at Aarhus University Hospital is thanked for their collaboration.

\section{Statement of Ethics}

This study was approved by the Research Ethics Committee of Central Denmark Region and the Danish Data Protection Agency. All of the patients gave their written informed consent. 


\section{Kidney \\ Blood Pressure \\ Research}

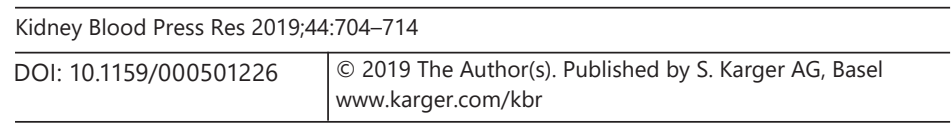

Carlsen et al.: Aortic Calcification and Central BP in CKD

\section{Disclosure Statement}

The authors have no conflict of interests to declare.

\section{Funding Sources}

This study was supported by the Aarhus Universitets Forskningsfond, the Grosserer L.F. Foghts Fond, and the Familien Hede Nielsens Fond. The funding had no impact on either data collection or analysis or the writing this paper.

\section{Author Contributions}

Rasmus K. Carlsen (principal investigator and main writer), Simon Winther (principal investigator of the ACToR study), Christian D. Peters (cosupervisor), Esben Laugesen (expert on central BP), Dinah S. Khatir (cosupervisor), Hans E. Bøtker (clinical primarily responsible for patients undergoing CAG), Morten Bøttcher (clinical primarily responsible of patients undergoing cardiac CT), Per Ivarsen (project designer), My Svensson (project designer), Niels H. Buus (main supervisor). Furthermore, all of the authors contributed according to the ICMJE Criteria for Authorship.

\section{References}

1 Collins R, Peto R, MacMahon S, Hebert P, Fiebach NH, Eberlein KA, et al. Blood pressure, stroke, and coronary heart disease. Part 2, Short-term reductions in blood pressure: overview of randomised drug trials in their epidemiological context. Lancet. 1990 Apr;335(8693):827-38.

2 Levin A, Stevens PE, Bilous RW, et al. KDIGO 2012 clinical practice guideline for the evaluation and management of chronic kidney disease, Kidney Int. 2013;3(1):1-150.

3 Pauca AL, O'Rourke MF, Kon ND. Prospective evaluation of a method for estimating ascending aortic pressure from the radial artery pressure waveform. Hypertension. 2001 Oct;38(4):932-7.

4 Cloud GC, Rajkumar C, Kooner J, Cooke J, Bulpitt CJ. Estimation of central aortic pressure by SphygmoCor requires intra-arterial peripheral pressures. Clin Sci (Lond). 2003 Aug;105(2):219-25.

5 Davies JI, Band MM, Pringle S, Ogston S, Struthers AD. Peripheral blood pressure measurement is as good as applanation tonometry at predicting ascending aortic blood pressure. J Hypertens. 2003 Mar;21(3):571-6.

6 Roman MJ, Devereux RB, Kizer JR, Lee ET, Galloway JM, Ali T, et al. Central pressure more strongly relates to vascular disease and outcome than does brachial pressure: the Strong Heart Study. Hypertension. 2007 Jul; 50(1):197-203.

7 McEniery CM, Yasmin, McDonnell B, Munnery M, Wallace SM, Rowe CV, et al.; Anglo-Cardiff Collaborative Trial Investigators. Central pressure: variability and impact of cardiovascular risk factors: the Anglo-Cardiff Collaborative Trial II. Hypertension. 2008 Jun;51(6):1476-82.

8 Smulyan H, Siddiqui DS, Carlson RJ, London GM, Safar ME. Clinical utility of aortic pulses and pressures calculated from applanated radial-artery pulses. Hypertension. 2003 Aug;42(2):150-5.

9 Weber T, Wassertheurer S, Rammer M, Maurer E, Hametner B, Mayer CC, et al. Validation of a brachial cuffbased method for estimating central systolic blood pressure. Hypertension. 2011 Nov;58(5):825-32.

10 Carlsen RK, Peters CD, Khatir DS, Laugesen E, Bøtker HE, Winther S, et al. Estimated aortic blood pressure based on radial artery tonometry underestimates directly measured aortic blood pressure in patients with advancing chronic kidney disease staging and increasing arterial stiffness. Kidney Int. 2016 Oct; 90 (4): 869-77.

11 Schlieper G, Schurgers L, Brandenburg V, Reutelingsperger C, Floege J. Vascular calcification in chronic kidney disease: an update. Nephrol Dial Transplant. 2016 Jan;31(1):31-9.

12 Levey AS, Stevens LA, Schmid CH, Zhang YL, Castro AF 3rd, Feldman HI, et al.; CKD-EPI (Chronic Kidney Disease Epidemiology Collaboration). A new equation to estimate glomerular filtration rate. Ann Intern Med. 2009 May;150(9):604-12.

13 Winther S, Svensson M, Jørgensen HS, Bouchelouche K, Gormsen LC, Pedersen BB, et al. Diagnostic Performance of Coronary CT Angiography and Myocardial Perfusion Imaging in Kidney Transplantation Candidates. JACC Cardiovasc Imaging. 2015 May;8(5):553-62. 
14 Agatston AS, Janowitz WR, Hildner FJ, Zusmer NR, Viamonte M Jr, Detrano R. Quantification of coronary artery calcium using ultrafast computed tomography. J Am Coll Cardiol. 1990 Mar;15(4):827-32.

15 Belghazi J, El Feghali RN, Moussalem T, Rejdych M, Asmar RG. Validation of four automatic devices for selfmeasurement of blood pressure according to the International Protocol of the European Society of Hypertension. Vasc Health Risk Manag. 2007;3(4):389-400.

16 Guérin AP, London GM, Marchais SJ, Metivier F. Arterial stiffening and vascular calcifications in end-stage renal disease. Nephrol Dial Transplant. 2000 Jul;15(7):1014-21.

17 Lanzer P, Boehm M, Sorribas V, Thiriet M, Janzen J, Zeller T, et al. Medial vascular calcification revisited: review and perspectives. Eur Heart J. 2014 Jun;35(23):1515-25.

18 Laugesen E, Rossen NB, Peters CD, Mæng M, Ebbehøj E, Knudsen ST, et al. Assessment of central blood pressure in patients with type 2 diabetes: a comparison between SphygmoCor and invasively measured values. Am J Hypertens. 2014 Feb;27(2):169-76.

19 Zuo JL, Li Y, Yan ZJ, Zhang RY, Shen WF, Zhu DL, et al. Validation of the central blood pressure estimation by the SphygmoCor system in Chinese. Blood Press Monit. 2010 Oct;15(5):268-74.

20 Laugesen E, Knudsen ST, Hansen KW, Rossen NB, Jensen LO, Hansen MG, et al. Invasively Measured Aortic Systolic Blood Pressure and Office Systolic Blood Pressure in Cardiovascular Risk Assessment: A Prospective Cohort Study. Hypertension. 2016 Sep;68(3):768-74.

21 Rahman M, Hsu JY, Desai N, Hsu CY, Anderson AH, Appel LJ, et al.; CRIC Study Investigators. Central Blood Pressure and Cardiovascular Outcomes in Chronic Kidney Disease. Clin J Am Soc Nephrol. 2018 Apr;13(4): 585-95. 